\title{
Reticulo-rumen temperature as a predictor of calving time in primiparous and parous Holstein females
}

\author{
J. B. G. Costa Jr., ${ }^{\star}$ J. K. Ahola, $\dagger^{1}$ Z. D. Weller, $\ddagger$ R. K. Peel, $†$ J. C. Whittier, $†$ and J. O. J. Barcellos* \\ *Department of Animal Science, Universidade Federal do Rio Grande do Sul, Porto Alegre, Brazil 91540 \\ †Department of Animal Sciences, and \\ ‡Department of Statistics, Colorado State University, Fort Collins 80523
}

\section{ABSTRACT}

The objective of this research was to define and analyze drops in reticulo-rumen temperature (Trr) as an indicator of calving time in Holstein females. Data were collected from 111 primiparous and 150 parous Holstein females between November 2012 and March 2013. Between -15 and $-5 \mathrm{~d}$ relative to anticipated calving date, each female received an orally administered temperature sensing reticulo-rumen bolus that collected temperatures hourly. Daily mean Trr was calculated from $\mathrm{d}-5$ to 0 relative to using all Trr values (A-Trr) or only Trr values $\geq 37.7^{\circ} \mathrm{C}$ (W-Trr) not altered by water intake. To identify a Trr drop, 2 methodologies for computing the baseline temperature were used. Generalized linear models (GLM) were used to estimate the probability of calving within the next 12 or $24 \mathrm{~h}$ for primiparous, parous, and all females, based on the size of the Trr drop. For all GLM, a large drop in Trr corresponded with a large estimated probability of calving. The predictive power of the GLM was assessed using receiver-operating characteristic (ROC) curves. The ROC curve analyses showed that all models, regardless of methodology in calculation of the baseline or tested category (primiparous or parous), were able to predict calving; however, area under the ROC curve values, an indication of prediction quality, were greater for methods predicting calving within $24 \mathrm{~h}$. Further comparisons between GLM for primiparous and parous, and using baseline 1 and 2, provide insight on the differences in predictive performance. Based on the GLM, Trr drops of $0.2,0.3$, and $0.4^{\circ} \mathrm{C}$ were identified as useful indicators of parturition and further analyzed using sensitivity, specificity, and diagnostic odds ratios. Based on sensitivity, specificity, and diagnostic odds ratios, the best indicator of calving was an average $\operatorname{Trr}$ drop $\geq 0.2^{\circ} \mathrm{C}$,

Received December 29, 2014.

Accepted February 9, 2016.

${ }^{1}$ Corresponding author: jason.ahola@colostate.edu regardless of methodology used to compute the baseline or category of animal evaluated.

Key words: dairy cow, parturition, reticulo-rumen temperature, receiver-operating characteristic curve performance test

\section{INTRODUCTION}

Intensification of milk production is the result of producers seeking more technological advancement, because dairy farms with a high-level of technological adoption show production costs $53 \%$ smaller than dairy farms with a low level of technological adoption (ElOsta and Morehart, 2000; USDA Economic Research Service, 2007). Between 2000 and 2005, an increase in dairy cow inventory, adoption of automated systems, and selection of animals with greater productive potential were major changes in the US milk production industry, increasing animal productivity by $8.2 \%$ (Khanal et al., 2010). However, sexual precocity of females and selection of bulls with high calf birth weight increased calving problems (Zaborski et al., 2009; Mee et al., 2011), affecting $22.6 \%$ of primiparous dairy females and $13.8 \%$ of the US dairy herd (Mee, 2008), which may result in lost milk production, reduced herd fertility, and increased risks of calf and dam mortality as showed in research done in United Kingdom (McGuirk et al., 2007).

Constant monitoring of animals during calving can help identify the appropriate moment for obstetric assistance, decreasing deaths of newborns by up to $50 \%$ as well as reducing losses caused by dystocia (Bellows et al., 1987). Nonetheless, an increase in labor cost has made this kind of monitoring burdensome for cattle producers (USDA Economic Research Service, 2007), making the adoption of an automated monitoring technology a viable option.

Various monitoring technologies for calving have been proposed (Wright et al., 1988; Matsas et al., 1992; Streyl et al., 2011). However, difficulties in their use made visualization of cow behavior the most frequent 
practice used to predict time of calving (Palombi et al., 2013). Previous studies have shown that body temperature in bovines dropped by up to $1^{\circ} \mathrm{C}$ before the beginning of the calving process (Lammolgia et al., 1997), and evaluation of different anatomic locations for temperature (vagina, rectum, skin, and reticulorumen) confirmed that hypothesis, showing that body temperature could be used as a calving predictor (Aoki et al., 2005; Burfeind et al., 2011; Cooper-Prado et al., 2011). Some of these locations, such as the vagina and rectum, can have low functionality for the producer due to the need for constant manual checks of body temperature, as well as a greater probability of the occurrence of lesions in these regions. However, collection of reticulo-rumen temperature ( $\mathbf{T r r}$ ) does not have these limitations because the sensor automatically collects Trr readings, the device is lodged in a location that does not cause damage to the animal, and the need for daily labor is reduced (Sievers et al., 2004). However, data collected by means of Trr technology must be analyzed to generate applicable results for a dairy producer.

The objectives of this study were to explore the potential use of change in Trr as a predictor of the timing of calving, determine a functional methodology to calculate and identify a change in Trr, and explore different levels of Trr change as an indicator of calving in primiparous and parous Holstein females.

\section{MATERIALS AND METHODS}

\section{Animals and Data Collection}

This experiment was previously submitted and approved by the Colorado State University Animal Care and Use Committee (protocol \#11-2583A). Between November 2012 and March 2013, 111 primiparous and 150 parous Holstein females from a commercial dairy farm in Platteville, Colorado, were used for data collection. Between -15 and -5 d relative to calving, females were relocated to a maternity pen near the milking parlor, and each female received an orally administered temperature-sensing reticulo-rumen bolus (Phase IV Engineering, Boulder, CO). Each sensor was cylindrical in shape, weighed $150 \mathrm{~g}$, and had a temperature sensor programmed to carry out a Trr reading every hour and store up to 12 readings. The telemetric system was equipped with 2 antennas with reach capacity of 90 $\mathrm{m}$ and located within the maternity pen. Therefore, complete records required that an animal be within the area of reach of the antennas between 2 and 3 times per day. From the antennas, readings were sent to a computer equipped with TempTrack software (DVM Systems, Greeley, CO), which stored data collected from
Trr monitoring. Cattle were continuously monitored for calving through visual observation by maternity personnel, and the time of calf delivery (e.g., actual expulsion of the fetus) was recorded.

\section{Statistical Analyses}

Day was defined relative to the time of calf delivery, with d 0 corresponding to the 24 -h period before birth. Daily average Trr from $-5 \mathrm{~d}$ relative to calving to the day of calving (d 0) was computed using all Trr readings (A-Trr) or only readings from $\operatorname{Trr} \geq 37.7^{\circ} \mathrm{C}$ (W-Trr) to analyze the effect of day on Trr. When $\operatorname{Trr} \leq 37.7^{\circ} \mathrm{C}$, it was believed that temperature decline was due to water consumption (Boehmer et al., 2009). These 2 data groups were analyzed separately using the PROC MIXED procedure of the SAS version 9.3 (SAS Institute Inc., Cary, NC), with animal category (primiparous vs. parous) and day as fixed effects. Comparisons of daily A-Trr and W-Trr means were determined by Scheffe's test (SAS Institute Inc.) with the level of significance at $P<0.05$.

For all of the remaining statistical analyses described, we use only W-Trr values occurring between $120(-5 \mathrm{~d})$ and $0 \mathrm{~h}$ before calving with the objective of capturing a drop in Trr in animals about to calve. This included 9,911 readings from 111 primiparous Holstein females and 12,351 readings from 150 parous Holstein cows. For each reading on a particular animal, 2 Trr baselines were calculated based on the time of $d$ the temperature reading was recorded. The first baseline (BL1) was the average Trr from the previous $4 \mathrm{~d}$ that occurred within a 1-h window of the observed reading time. For example, if an animal's temperature was recorded at 1000 $\mathrm{h}$ on Friday, the corresponding BL1 temperature was the average of the same animal's temperatures recorded between 0930 and $1030 \mathrm{~h}$ on Monday through Thursday (this calculation typically included 2 to 4 data points). The second baseline (BL2) was the average Trr from the previous $4 \mathrm{~d}$ that occurred within a 5 -h window of the observed reading time (this calculation typically included 10 to 20 data points).

After generating both BL1 and BL2, the difference between baseline and current Trr readings was calculated, $\Delta \operatorname{Trr}_{1}$ and $\Delta \operatorname{Trr}_{2}$. A negative value of $\Delta \operatorname{Trr}$ indicated that the observed Trr was smaller than the baseline, indicating a drop in temperature. To capture a series of drops in Trr, we defined the value TempChange as the average of the current $\Delta \operatorname{Trr}$ value and $\Delta$ Trr values observed over the last $2 \mathrm{~h}$, if available. For example, the TempChange value corresponding to a temperature reading at $1000 \mathrm{~h}$ was the average of $\Delta$ Trr at $1000 \mathrm{~h}$ and any $\Delta \operatorname{Trr}$ values calculated for the same animal between 0800 and $1000 \mathrm{~h}$ on the same day 
(the calculation of TempChange typically included 2 to $3 \Delta$ Trr values). The TempChange values were computed for both baselines.

Generalized linear models (GLM; McCullagh and Nelder, 1989) were used to estimate the probability of calving given the change in Trr, and these models were evaluated using receiver-operating characteristic (ROC) curves (Zweig and Campbell, 1993). In analyzing these data, we made several simplifying assumptions to avoid a highly technical analysis. For example, we did not model the serial correlation in the data. A sensitivy analysis (not included) indicated that our conclusions are robust to the correlation. In practice, an algorithm for predicting calving needs to account for more complicated structure (e.g., water effect, correlation, periodicity, and so on) in the data, and the practical implications for providing an alarm for calving (e.g., a cost function for false positives/negative and having to move animals). The problem of creating a prediction algorithm to be used in practice was beyond the scope of this study. Although our methods are not completely appropriate for a prediction algorithm in the field, our analyses provide insight into 2 important questions: (1) are changes in Trr significantly related to the likelihood of calving? and (2) do changes in Trr have any predictive ability for distinguishing between an animal that is likely to calve and one that is not? The GLM and ROC analyses answer these questions.

For both baselines, we estimated a logistic regression model, a GLM, using an indicator of whether or not the animal calved within the next 12 or $24 \mathrm{~h}$ as the random, binary response $(\mathrm{Y}=1$ for calving, $\mathrm{Y}=0$ for not calving) and the TempChange $(\mathrm{X})$ variable as the continuous predictor. In the model, $\mathrm{E}[\mathrm{Y}]$ was the expected value, or mean, of $Y$, $\alpha$ was the regression coefficient representing the intercept term, and $\beta$ was the regression coefficient relating TempChange to the probability of calving. Using the logit link function, the GLM modeled the probability of calving, denoted $\pi$, given a value of TempChange via

$$
\text { probability of calving }=\pi=\mathrm{E}[\mathrm{Y}]=\frac{\mathrm{e}^{\alpha+\beta(\text { TempChange })}}{1+\mathrm{e}^{\alpha+\beta(\text { TempChange })}} \text {. }
$$

Separate GLM were estimated for each of 2 responses (calving within 12 and $24 \mathrm{~h}$ ), 2 predictors (TempChange from BL1 and BL2), and 3 animal categories (primiparous, parous, or all animals), totaling 12 models.

The maximum likelihood estimates of the $\alpha$ and $\beta$ parameters in equation [1] were computed using the GLM function in the statistical software R (R Development Core Team, 2008, Vienna, Austria). The $\beta$ pa- rameter was of interest because this parameter related TempChange to the probability of calving. Specifically, we tested the hypothesis that $\beta<0$ because this would indicate that the probability of calving increased as TempChange decreased (i.e., as TempChange became more negative, indicating a drop in Trr). For each GLM, we provided the estimate and 95\% confidence interval for $\beta$.

Given an animal's temperature, we computed the estimated probability of calving by calculating TempChange and plugging TempChange and the estimated $\alpha$ and $\beta$ parameters into equation [1]. We defined a positive test (i.e., an "alarm" for calving within the next 12 or $24 \mathrm{~h}$ ) if this probability exceeded a fixed threshold (which corresponded to a threshold value of TempChange). Sensitivity (Se) and specificity (Sp) were used to evaluate the performance of our predictions. For a given probability (TempChange) threshold, Se was the probability of a positive test (sounding the alarm) given that the animal would calve in the next " $\mathrm{h}$ " h (Martinez et al., 2003; Kumar and Indrayan, 2011). For a given probability (TempChange) threshold, Sp was the probability of a negative test (not sounding the alarm) given that the animal would not calve in the next "h" h (Martinez et al., 2003; Kumar and Indrayan, 2011). The closer the Se and Sp were to 1 , the better the predictive power.

We used ROC curves to evaluate the ability for TempChange to predict calving through the logistic regression models. The ROC curves plot $1-\mathrm{Sp}$ (on the $\mathrm{x}$-axis) versus $\mathrm{Se}$ (on the y-axis), generating the curve by plotting these values corresponding to different probability (TempChange) thresholds (Obuchowski, 2003; Kumar and Indrayan, 2011). A test with perfect predictive ability $(\mathrm{Se}=\mathrm{Sp}=1)$ would pass through the $(\mathrm{x}, \mathrm{y})$ point $(0,1)$. The closer the ROC curve came to this point, the better the predictive power of the GLM. The area under the ROC curve (AUC) provided an indicator of predictive power and was used to compare the predictive power of different models. An AUC greater than 0.5 indicated that TempChange provided better predictions (classifications) than random guessing (i.e., flipping a coin). For each GLM, we computed the AUC and a 95\% confidence interval through bootstrapping by using routines in the $\mathrm{R}$ packages "verification" (NCAR-Research Applications Laboratory, 2014) and "pROC" (Robin et al., 2011).

Finally, to identify the size of the drop in Trr useful for indicating calving, we further evaluated the GLM. For each GLM, we analyzed the predictive performance corresponding to 3 different thresholds for defining a positive test by computing $\mathrm{Se}, \mathrm{Sp}$, and diagnostic odds ratio (DOR) for the following values of TempChange: $\leq-0.2, \leq-0.3$, and $\leq-0.4^{\circ} \mathrm{C}$. For example, 

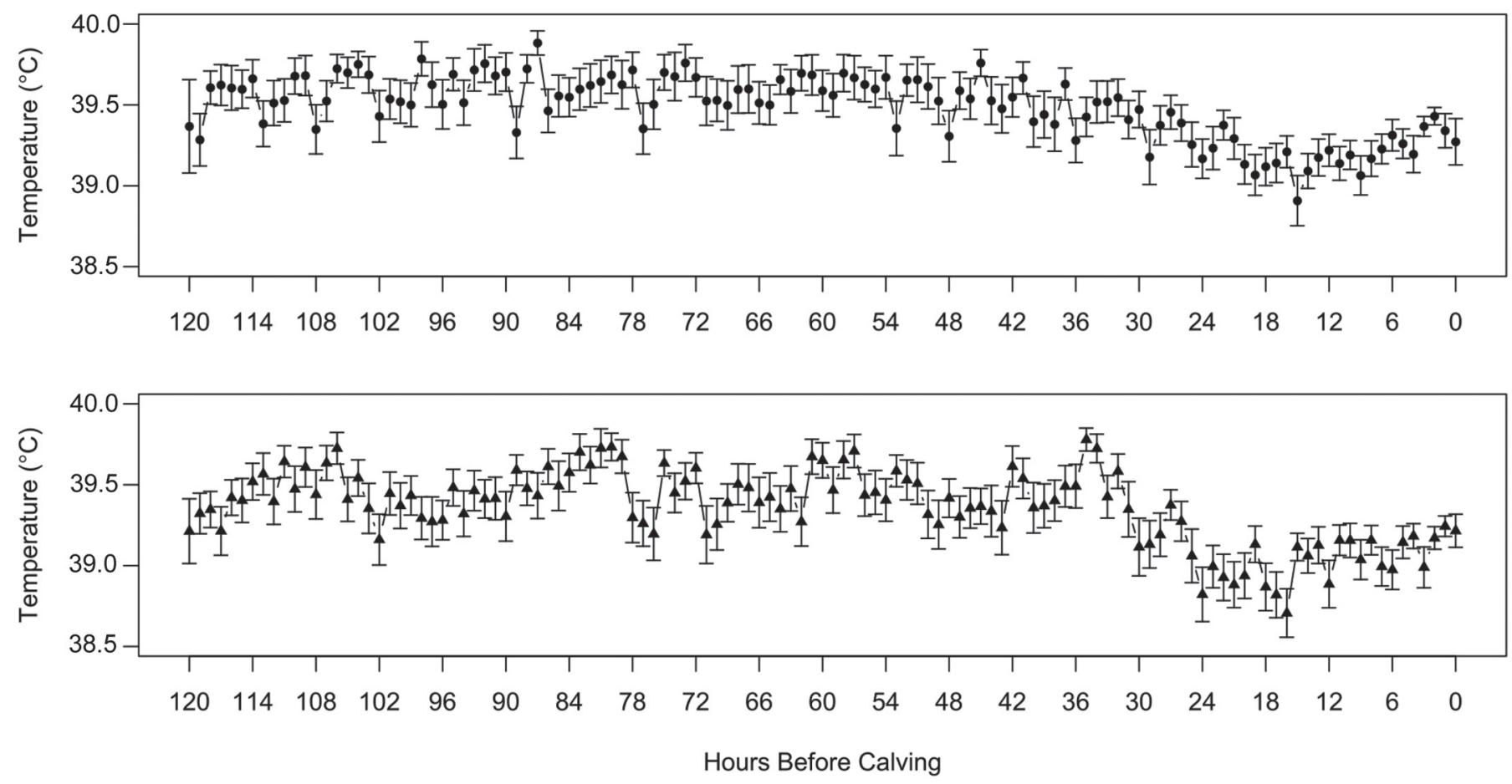

Figure 1. Hourly mean $( \pm \mathrm{SE})$ reticulo-rumen temperature (Trr), with all Trr values in primiparous $(\bullet)$ and parous $(\boldsymbol{\Lambda})$ Holstein females, from $120 \mathrm{~h}$ precalving through calving $(0 \mathrm{~h})$.

if a threshold of $-0.2^{\circ} \mathrm{C}$ was used, then a positive test (an alarm for calving within 12 or $24 \mathrm{~h}$ ) occurred when the observed TempChange was less than or equal to $-0.2^{\circ} \mathrm{C}$. The DOR (Glas et al., 2003) provided a single summary for test performance, taking into account the $\mathrm{Se}, \mathrm{Sp}$, and relative frequency of incidences of calving in the data. A value of 1 for the DOR indicated that predictions were no better than random guessing. The larger the value of DOR, the greater the discriminatory power of the test (predictions). We used $\mathrm{R}$ to calculate the confidence interval of the performance summaries.

\section{RESULTS AND DISCUSSION}

Hourly mean $( \pm \mathrm{SE})$ Trr for primiparous and parous Holstein females were graphed for A-Trr (Figure 1) and W-Trr (Figure 2) data, from $120 \mathrm{~h}$ precalving through calving $(0 \mathrm{~h})$. A decreasing trend was found in average Trr starting approximately $28 \mathrm{~h}$ before calving (Figures 1 and 2). Daily means and associated statistics for A-Trr and W-Trr are reported in Table 1. Tests for significant differences in daily mean A-Trr and W-Trr within parous Holstein cows and within primiparous Holstein females indicated a significantly lower mean A-Trr and W-Trr on d 0 (calving day) relative to all other days. For W-Trr, primiparous Holstein females also exhibited a significantly lower mean temperature on $\mathrm{d}-1$ relative to $\mathrm{d}-5$ through $\mathrm{d}-2(P<0.05)$. For all other comparisons, mean Trr temps were not significantly different on $\mathrm{d}-5$ through $\mathrm{d}-1(P>0.05$; Table 1).

In the current study, average W-Trr indicated a drop in temperature in the 24 to $48 \mathrm{~h}$ before calving, agreeing with results in previous studies that evaluated Trr (Cooper-Prado et al., 2011) and other anatomical areas (Aoki et al., 2005; Burfeind et al., 2011). The removal of Trr below $37.7^{\circ} \mathrm{C}$ reduced the mean SE by almost one-half, enabling the detection of the signal of significant differences in mean W-Trr among $\mathrm{d}-2,-1$, and 0 in primiparous Holstein females. Using all (ATrr) readings introduced greater variability (i.e., more "noise") in the data relative to using W-Trr, and thus it was harder to detect changes in Trr over time. The greater variance of $\mathrm{A}$-Trr compared with $\mathrm{W}$-Trr can be the consequence of bouts of water intake, which has previously been associated with transient reduction in reticulo-rumen temperature (Dye, 2005; Cooper-Prado et al., 2011). The drop in reticulo-rumen temperature can reach $8.5^{\circ} \mathrm{C}$ depending on the temperature and volume of water consumed (Bewley et al., 2008). Because we were attempting to capture the Trr drop that occurred at the beginning of calving, we removed tem- 

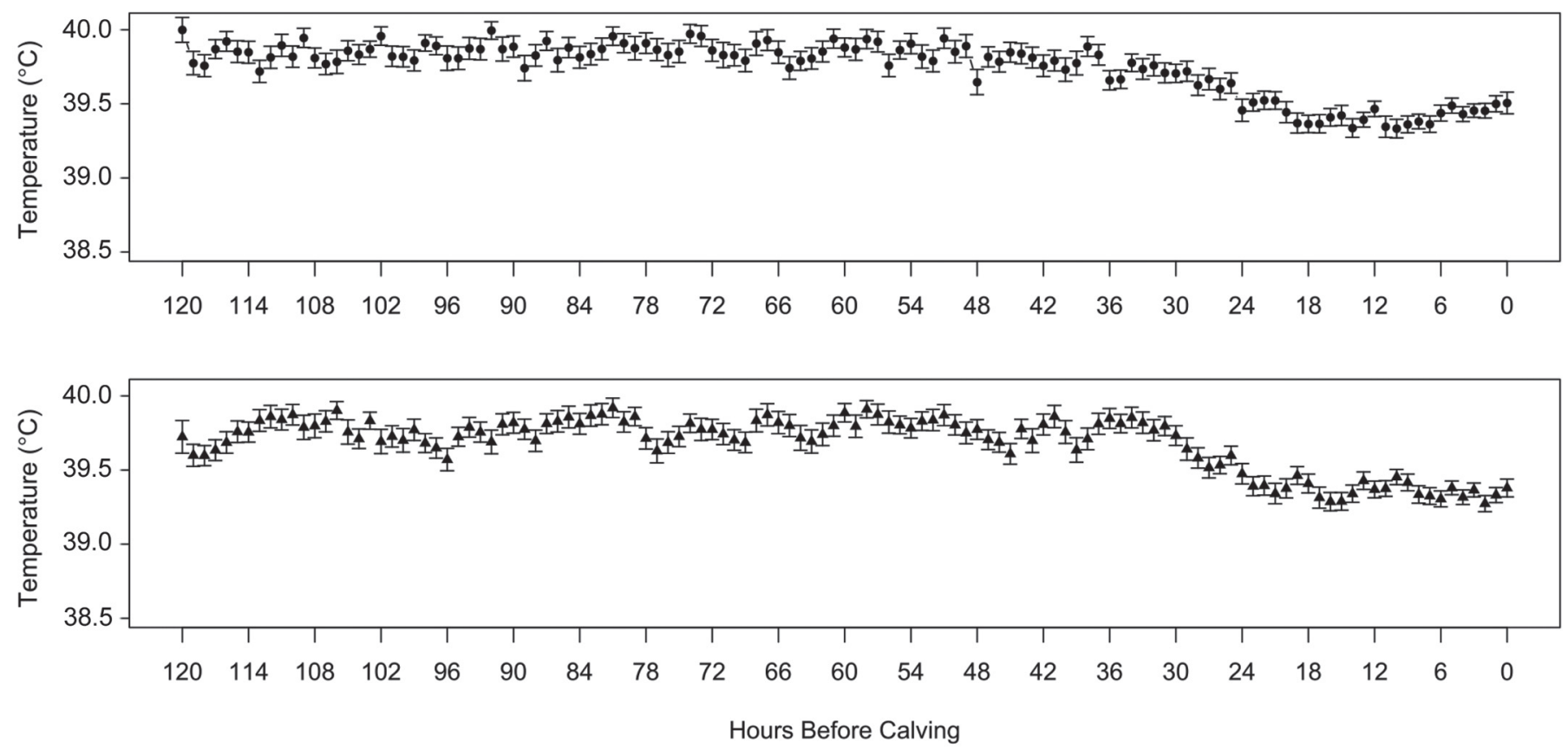

Figure 2. Hourly mean $( \pm \mathrm{SE})$ reticulo-rumen temperature (Trr), without $\operatorname{Trr} \leq 37.7^{\circ} \mathrm{C}$ in primiparous $(\bullet)$ and parous $(\boldsymbol{\Delta})$ Holstein females, from $120 \mathrm{~h}$ precalving through calving $(0 \mathrm{~h})$. The Trr temperatures below $37.7^{\circ} \mathrm{C}$ were removed because they were considered to be affected by water intake (Boehmer et al., 2009).

perature readings believed to be caused by water intake to avoid Trr changes due to water intake (Boehmer et al., 2009).

In both primiparous and parous Holstein females, average A-Trr dropped at least $0.25^{\circ} \mathrm{C}$ from $\mathrm{d}-1$ to 0 (Table 1). However, upon analyzing the W-Trr data, we observed that the difference between the average on $\mathrm{d}-1$ and $\mathrm{d} 0$ was 0.32 and $0.36^{\circ} \mathrm{C}$ for primiparous and parous Holstein females, respectively (Table 1). Furthermore, over a 48 -h period, a mean difference of $0.44^{\circ} \mathrm{C}$ from $\mathrm{d}-2$ to 0 was observed in primiparous Holstein females, which was greater than that reported by Cooper-Prado et al. (2011) for Angus cows. Dairy cows exhibit an even higher body temperature than beef cows as result of metabolic heat produced by greater nutritional intake (Kadzere et al., 2002; Robertshaw, 2004). The difference in metabolic heat produced may partially explain the difference in Trr drop between breeds.

Precalving drop of body temperature is a result of regulation of the obligatory thermogenesis (rate of basal metabolism) and facultative thermogenesis (production above the metabolism rate). These are activated by thyroid hormones and catecholamines (Silva, 2003, 2006), as well as sexual hormones which directly regulate facultative thermogenesis, furthering its inhibition or stimulation (Stachenfeld et al., 2000; Hampl et al., 2006). During gestation, progesterone $\left(\mathbf{P}_{4}\right)$ concentra-

Table 1. Mean daily reticulo-rumen temperature (Trr; LSM \pm SE) for $5 \mathrm{~d}$ before calving (d 0) in primiparous and parous Holstein females using all Trr values and only $\operatorname{Trr} \geq 37.7^{\circ} \mathrm{C}$

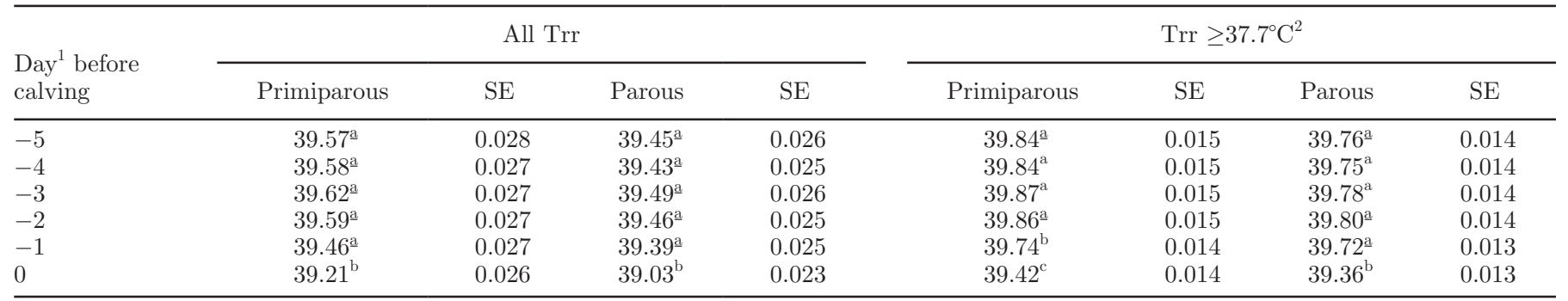

${ }^{\mathrm{a}-c}$ Means within a column without common superscripts differ $(P<0.05)$.

${ }^{1}$ For each animal, day was defined relative to the time of calving (e.g., d 0 was the 24-h period before giving birth).

${ }^{2}$ Trr temperatures below $37.7^{\circ} \mathrm{C}$ were removed because they were considered to be affected by water intake (Boehmer et al., 2009). 
Table 2. Performance measures (given in percentage ${ }^{1} ; 95 \%$ CI in parentheses) using reticulo-rumen temperature (Trr) as a predictor of calving within 12 or $24 \mathrm{~h}$ in primiparous Holstein females ${ }^{2}$

\begin{tabular}{|c|c|c|c|c|c|}
\hline $\begin{array}{l}\text { TempChange } \\
\text { alarm threshold }\end{array}$ & $\begin{array}{l}\text { Performance } \\
\text { measure }\end{array}$ & \multicolumn{2}{|c|}{ Baseline $1^{3}$} & \multicolumn{2}{|c|}{ Baseline $2^{4}$} \\
\hline$\leq-0.2^{\circ} \mathrm{C}$ & $\begin{array}{l}\mathrm{Se}^{5} \\
\mathrm{Sp}^{6} \\
\mathrm{DOR}^{7}\end{array}$ & $\begin{array}{l}69(67-71) \\
69(68-70) \\
5.00(4.98-5.03)\end{array}$ & $\begin{array}{l}69(66-71) \\
65(64-66) \\
4.02(3.99-4.06)\end{array}$ & $\begin{array}{l}69(68-70) \\
69(68-70) \\
5.11(5.08-5.14)\end{array}$ & $\begin{array}{l}70(67-72) \\
65(64-66) \\
4.24(4.20-4.28)\end{array}$ \\
\hline$\leq-0.3^{\circ} \mathrm{C}$ & $\begin{array}{l}\text { Se } \\
\text { Sp } \\
\text { DOR }\end{array}$ & $\begin{array}{l}62(60-64) \\
76(75-77) \\
4.99(4.97-5.02)\end{array}$ & $\begin{array}{l}62(59-64) \\
72(71-72) \\
4.01(3.97-4.04)\end{array}$ & $\begin{array}{l}61(59-63) \\
76(75-77) \\
4.91(4.89-4.93)\end{array}$ & $\begin{array}{l}61(58-64) \\
71(70-72) \\
3.86(3.83-3.90)\end{array}$ \\
\hline
\end{tabular}

${ }^{1} \mathrm{DOR}$ and $\mathrm{AUC}$ are not given as percentages.

${ }^{2}$ Measures of predictive performance are given at 3 TempChange drop thresholds for 2 baselines and 2 prediction times.

${ }^{3}$ Baseline 1 = average of readings for 4 previous days using a $1 \mathrm{~h}$ window from the current reading. Differences in observed temperature and baseline 1 were used to calculate TempChange.

${ }^{4}$ Baseline 2 = average of readings for 4 previous days using a $5 \mathrm{~h}$ window from the current reading. Differences in observed temperature and baseline 2 were used to calculate TempChange.

${ }^{5} \mathrm{Se}=$ sensitivity, the probability of a positive test (i.e., calving alarm) given that the primiparous female will calve in the next 24 or $12 \mathrm{~h}$; larger values indicate greater predictive power.

${ }^{6} \mathrm{Sp}=$ specificity, the probability of a negative test (i.e., no calving alarm), given that the primiparous female will not calve within the next 24 or $12 \mathrm{~h}$; larger values indicate greater predictive power.

${ }^{7} \mathrm{DOR}=$ diagnostic odds ratio, a summary of Se and Sp. Larger values indicate greater predictive power.

${ }^{8}$ Measure of predictive performance for the entire generalized linear model (GLM).

${ }^{9} \mathrm{AUC}=$ area under the receiver operator characteristics curve. Considers all possible TempChange thresholds. Values larger than 0.50 indicate the test (predictions) have discriminatory power.

tion is greater due to its production by the corpus luteum, with blood plasma values of 2.5 to $14.0 \mathrm{ng} /$ $\mathrm{mL}$ from the beginning to the final third of gestation in which there is a gradual drop in the concentration to 1.0 and $1.5 \mathrm{ng} / \mathrm{mL}$ of blood plasma $1 \mathrm{~d}$ before calving (Wettemann and Hafs, 1973; Lammoglia et al., 1997; Shah et al., 2007). Nevertheless, estrogen concentration is between 3 and $30 \mathrm{pg} / \mathrm{mL}$ in blood plasma until midway through gestation, with a subsequent increase to between 250 and $295 \mathrm{pg} / \mathrm{mL} 282$ d into gestation (Smith et al., 1973; Patel et al., 1999).

The increased $\mathrm{P}_{4}$ concentration during gestation acts on thermosensitive cells in the preoptic area of the hypothalamus, inhibiting neurons sensitive to heat and activating neurons sensitive to cold, which inhibits mechanisms of heat loss and activates mechanisms of heat production during gestation (Nakayama et al., 1975; Tsai et al., 1988). However, the progressive increase in estrogen concentration in the final third of gestation stimulates heat-sensitive cells in the regulation of $\mathrm{P}_{4}$ thermogenic modulation, favoring inhibition of cold-sensitive cells (Czaja and Butera, 1986; Tsai et al., 1992; Stachenfeld et al., 2000), which can cause body temperature drop and, consequently, a drop in precalving Trr.

Summaries of performance measures for using TempChange to predict calving for primiparous, parous, and these 2 categories combined are included in Tables 2, 3 , and 4 , respectively. The ROC curves for each GLM are included in Figures 3, 4, and 5. Table 5 includes estimates and confidence intervals for $\beta$ for each of the GLM. For every GLM, a test of $\beta<0$ indicated a statistically significant relationship between TempChange and the probability of calving $(P<0.001)$. Thus, regardless of the baseline (1 vs. $5 \mathrm{~h}$ window) used, animal category (primiparous vs. parous vs. all animals) or the prediction time (12 vs. $24 \mathrm{~h}$ ), changes in W-Trr can be used to inform the likelihood of calving. Furthermore, because data support the conclusion that $\beta<0$, the larger the drop in Trr, the larger the estimated probability of calving (Tables 2, 3, and 4; Figures 2, 3, and 4).

For each of the GLM, the point estimates of the AUC were between 0.71 and 0.75 . As a measure of the quality of predictions, AUC values can be classified as poor (0.6 to 0.7 ), usable (0.71 to 0.8$)$, good (0.81 to 0.9 ), and excellent (0.91 to 1.0; Zhu et al., 2010). The GLM modeling the probability of calving occurring within 24 $\mathrm{h}$ showed greater AUC values, regardless of the animal category or the baseline used to compute TempChange (Tables 2, 3, and 4). Intuitively, this implies that it was easier to make a prediction that said, "the animal will calve in the next $24 \mathrm{~h}$ " than to make a prediction that said, "the animal will calve in the next $12 \mathrm{~h}$." The larger 
Table 3. Performance measures (given in percentage ${ }^{1}$; $95 \%$ CI in parentheses) using reticulo-rumen temperature (Trr) as a predictor of calving within 12 or $24 \mathrm{~h}$ in parous Holstein cows ${ }^{2}$

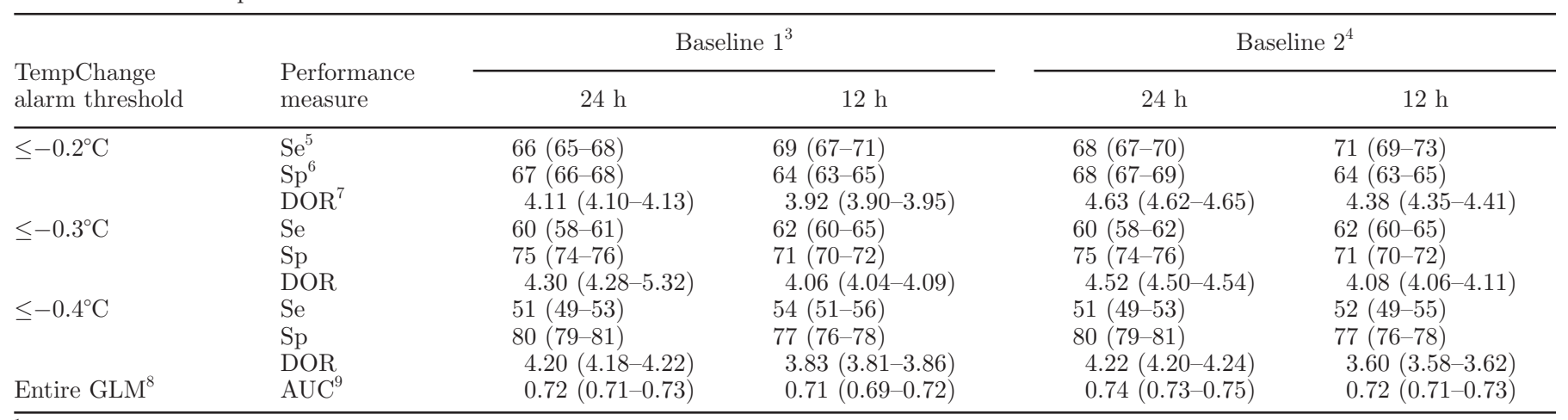

${ }^{1} \mathrm{DOR}$ and $\mathrm{AUC}$ are not given as percentages.

${ }^{2}$ Measures of predictive performance are given at 3 TempChange drop thresholds for 2 baselines and 2 prediction times.

${ }^{3}$ Baseline 1 = average of readings for 4 previous days using a $1 \mathrm{~h}$ window from the current reading. Differences in observed temperature and baseline 1 were used to calculate TempChange.

${ }^{4}$ Baseline 2 = average of readings for 4 previous days using a $5 \mathrm{~h}$ window from the current reading. Differences in observed temperature and baseline 2 were used to calculate TempChange.

${ }^{4} \mathrm{Se}=$ sensitivity, the probability of a positive test (i.e., calving alarm) given that the parous cow will calve in the next 24 or $12 \mathrm{~h}$; larger values indicate greater predictive power.

${ }^{5} \mathrm{Sp}=$ specificity, the probability of a negative test (i.e., no calving alarm), given that the parous cow will not calve within the next 24 or 12 h; larger values indicate greater predictive power.

${ }^{6} \mathrm{DOR}=$ diagnostic odds ratio, a summary of Se and Sp. Larger values indicate greater predictive power.

${ }^{7}$ Measure of predictive performance for the entire generalized linear model (GLM).

${ }^{8} \mathrm{AUC}=$ area under the receiver operator characteristics curve. Considers all possible TempChange thresholds. Values larger than 0.50 indicate the test (predictions) have discriminatory power.

Table 4. Performance measures (given in percentage ${ }^{1}$; $95 \%$ CI in parentheses) using reticulo-rumen temperature (Trr) as a predictor of calving within 12 or $24 \mathrm{~h}$ for all Holstein females ${ }^{2}$

\begin{tabular}{|c|c|c|c|c|c|}
\hline \multirow{2}{*}{$\begin{array}{l}\text { TempChange } \\
\text { alarm threshold }\end{array}$} & \multirow{2}{*}{$\begin{array}{l}\text { Performance } \\
\text { measure }\end{array}$} & \multicolumn{2}{|c|}{ Baseline $1^{3}$} & \multicolumn{2}{|c|}{ Baseline $2^{4}$} \\
\hline & & $24 \mathrm{~h}$ & $12 \mathrm{~h}$ & $24 \mathrm{~h}$ & $12 \mathrm{~h}$ \\
\hline \multirow{2}{*}{$\leq-0.2^{\circ} \mathrm{C}$} & $\mathrm{Sp}^{6}$ & $67(68-69)$ & $64(63-65)$ & $69(68-70)$ & $64(63-65)$ \\
\hline & $\mathrm{DOR}^{7}$ & $4.50(4.49-4.51)$ & $3.97(3.95-3.98)$ & $4.85(4.84-4.86)$ & $4.32(4.30-4.34)$ \\
\hline \multirow{2}{*}{$\leq-0.3^{\circ} \mathrm{C}$} & $\mathrm{Se}$ & $60(59-62)$ & $62(60-64)$ & $61(59-62)$ & $62(60-63)$ \\
\hline & $\mathrm{Sp}$ & $75(74-76)$ & $71(70-72)$ & $75(74-76)$ & $71(70-72)$ \\
\hline \multirow{2}{*}{$\leq-0.4^{\circ} \mathrm{C}$} & $\mathrm{Sp}$ & $81(80-82)$ & $77(76-78)$ & $81(80-82)$ & $77(76-78)$ \\
\hline & DOR & $4.44(4.43-4.45)$ & $3.77(3.76-3.79)$ & $4.46(4.45-4.47)$ & $3.71(3.69-3.72)$ \\
\hline Entire $\mathrm{GLM}^{8}$ & $\mathrm{AUC}^{9}$ & $0.73(0.72-0.74)$ & $0.71(0.70-0.72)$ & $0.74(0.73-0.75)$ & $0.72(0.71-0.73)$ \\
\hline
\end{tabular}

${ }^{1} \mathrm{DOR}$ and AUC are not given as percentages.

${ }^{2}$ Measures of predictive performance are given at 3 TempChange drop thresholds for 2 baselines and 2 prediction times.

${ }^{3}$ Baseline 1 = average of readings for 4 previous days using a $1 \mathrm{~h}$ window from the current reading. Differences in observed temperature and baseline 1 were used to calculate TempChange.

${ }^{4}$ Baseline 2 = average of readings for 4 previous days using a $5 \mathrm{~h}$ window from the current reading. Differences in observed temperature and baseline 2 were used to calculate TempChange.

${ }^{5} \mathrm{Se}=$ sensitivity, the probability of a positive test (i.e., calving alarm) given that the animal will calve in the next 24 or $12 \mathrm{~h}$; larger values indicate greater predictive power.

${ }^{6} \mathrm{Sp}=$ specificity, the probability of a negative test (i.e., no calving alarm), given that the animal will not calve within the next 24 or $12 \mathrm{~h}$; larger values indicate greater predictive power.

${ }^{7} \mathrm{DOR}=$ diagnostic odds ratio, a summary of Se and Sp. Larger values indicate greater predictive power.

${ }^{8}$ Measure of predictive performance for the entire generalized linear model (GLM).

${ }^{9} \mathrm{AUC}=$ area under the receiver operator characteristics curve. Considers all possible TempChange thresholds. Values larger than 0.50 indicate the test (predictions) have discriminatory power. 
prediction window allowed more room for prediction error. The 2 baseline options produced very similar AUC values, indicating that the 2 options were both successful at defining a baseline to compute TempChange. Finally, primiparous Holstein females tended to exhibit slightly larger AUC values relative to parous Holstein cows. This difference can be partially explained by the significant decrease in mean W-Trr in the $2 \mathrm{~d}(0 \mathrm{~d}$, $-1 \mathrm{~d}$ ) before calving in primiparous Holstein females, where this same decrease was not seen in parous Holstein cows (Table 1). The decrease in mean W-Trr over $2 \mathrm{~d}$ tended to provide more opportunities for a positive test (i.e., sound the alarm) for calving. The AUC values observed in this analysis were below what was observed by Burfeind et al. (2011), who evaluated vaginal and

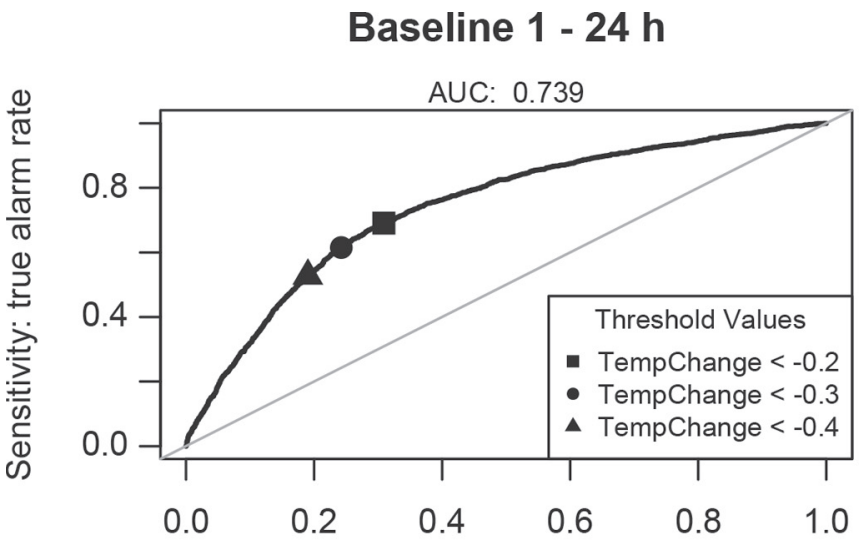

(1 - Specificity): false alarm rate

Baseline 2 - $24 \mathrm{~h}$

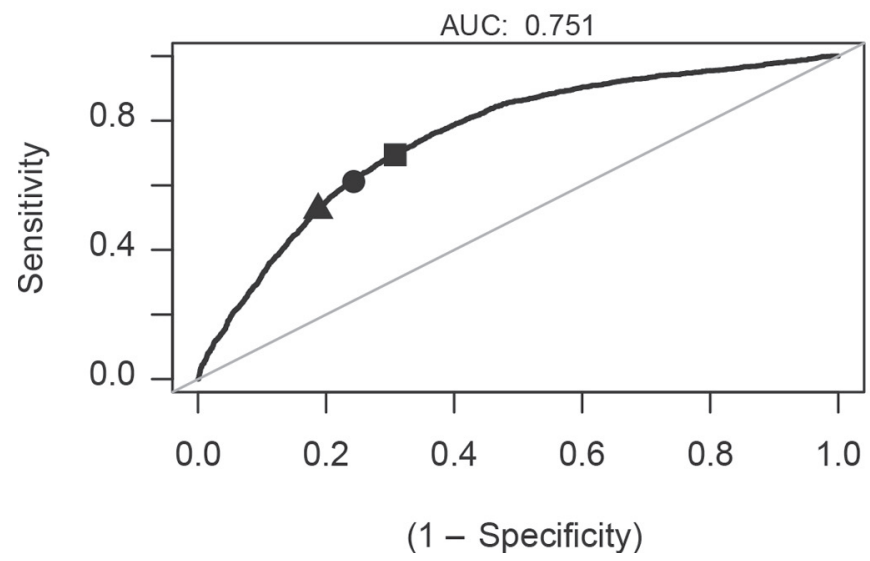

rectal temperature in Holstein cows. The regions evaluated may explain this difference in AUC values between the 2 studies, as vaginal and rectal regions can show less variation in temperature than Trr, which can have more variation due to ruminal fermentation.

To further explore how changes in Trr might be used to predict time of calving, and how differences in baseline, animal category, and prediction time affect predictions, we calculated performance measures using 3 specific thresholds of TempChange as an alarm for calving. We used TempChange thresholds of -0.2 , -0.3 , and $-0.4^{\circ} \mathrm{C}$ from both BL1 and BL2, and used these values to test for calving within the next " $h$ " $h$ $(\mathrm{h}=12,24)$ for each animal category. For example, if an animal exhibited a TempChange $<-0.3^{\circ} \mathrm{C}$, we had
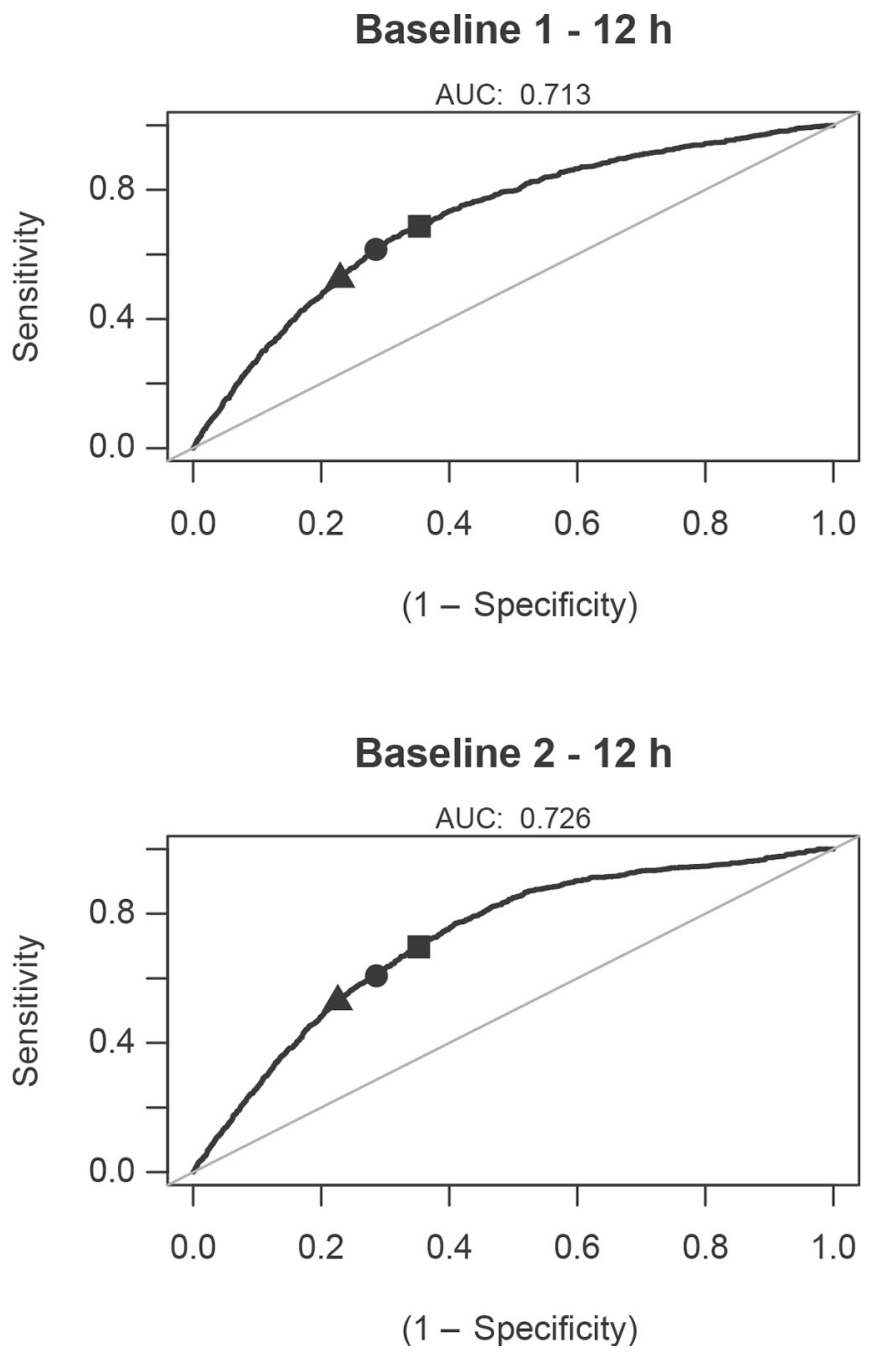

Figure 3. Receiver-operating characteristic curves using TempChange to predict calving within 24 and $12 \mathrm{~h}$ for primiparous Holstein females. TempChange quantifies the decrease in reticulo-rumen temperature relative to a baseline. Baseline $1=$ average of readings for 4 previous days using a 1-h window from the current reading. Baseline $2=$ average of readings for 4 previous days using a 5 -h window from the current reading. An area under the curve $(\mathrm{AUC})>0.50$ indicates that TempChange (reticulo-rumen temperature) provides a better prediction than random guessing. 
a positive test that the animal would calve in the next $24 \mathrm{~h}$ (i.e., sound the alarm for calving). This test would occur each time a new temperature was received. In practice, a method for producing calving notifications would need account for more complicated structure in the data and the practical implications for providing an alarm for calving. Furthermore, we had data from 120 to $0 \mathrm{~h}$ before calving. In practice, we would not know when the $0 \mathrm{~h}$ would occur, and we would need to rely on breeding records to implement a prediction algorithm. Although our methods were not completely appropriate to be used as a prediction algorithm in the field, our analyses provided insights into the size of the change in Trr that might be indicative of calving, and comparisons in the quality of predictions for different baselines, animals, and prediction times.

The Se and Sp corresponding to each threshold are plotted on the ROC curves in Figures 3, 4, and 5. We first noted the differences in prediction quality for the different TempChange thresholds. Using a threshold of $-0.4^{\circ} \mathrm{C}$, false alarms (high $\mathrm{Sp}$ ) would rarely be made, but many of the animals do not exhibit this

\section{Baseline 1 - 24 h}

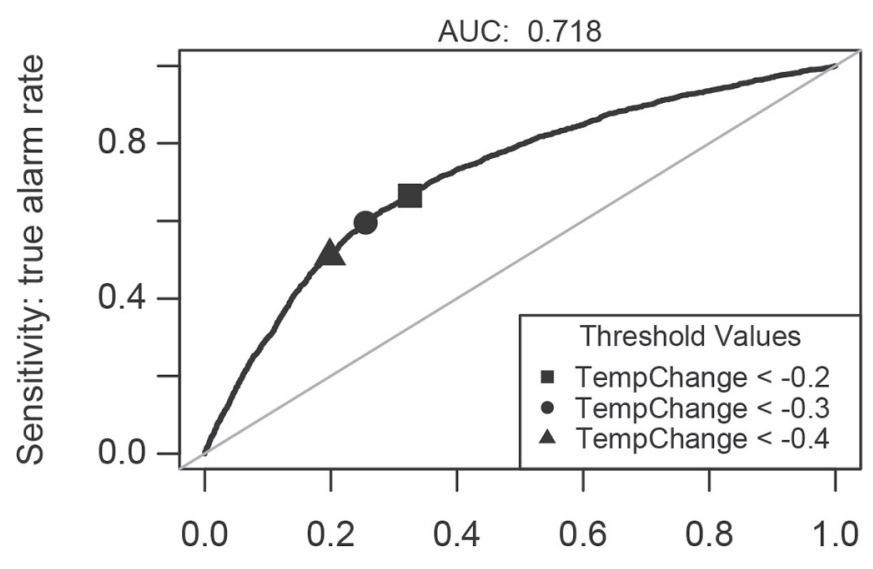

(1 - Specificity): false alarm rate

\section{Baseline 2 - $24 \mathrm{~h}$}

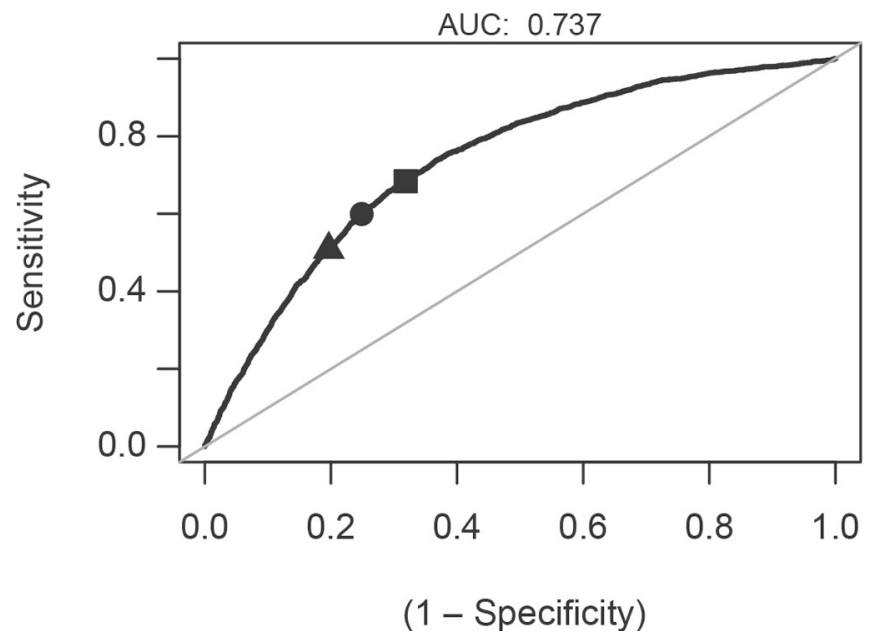

Baseline 1 - $12 \mathrm{~h}$

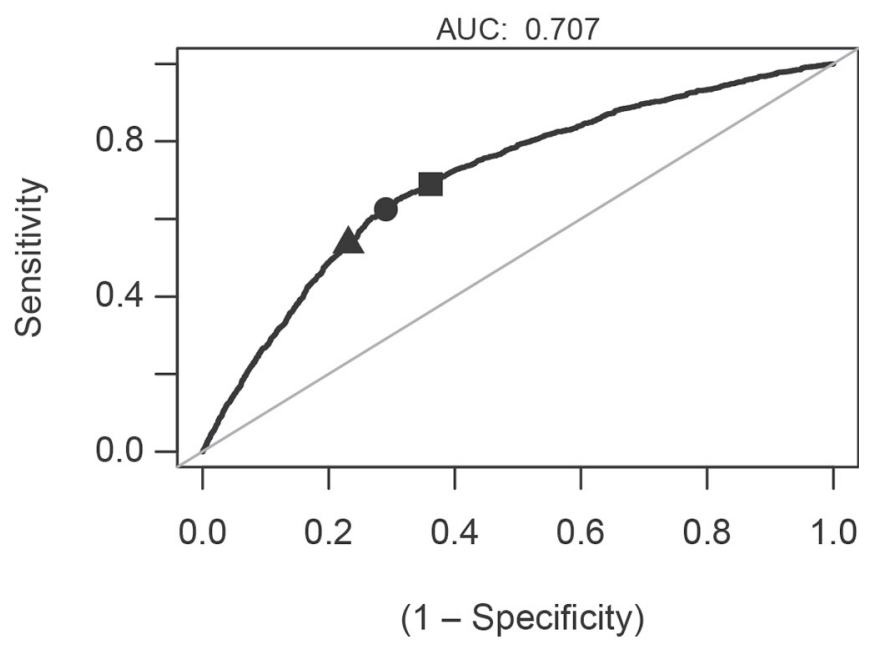

Baseline 2 - $12 \mathrm{~h}$

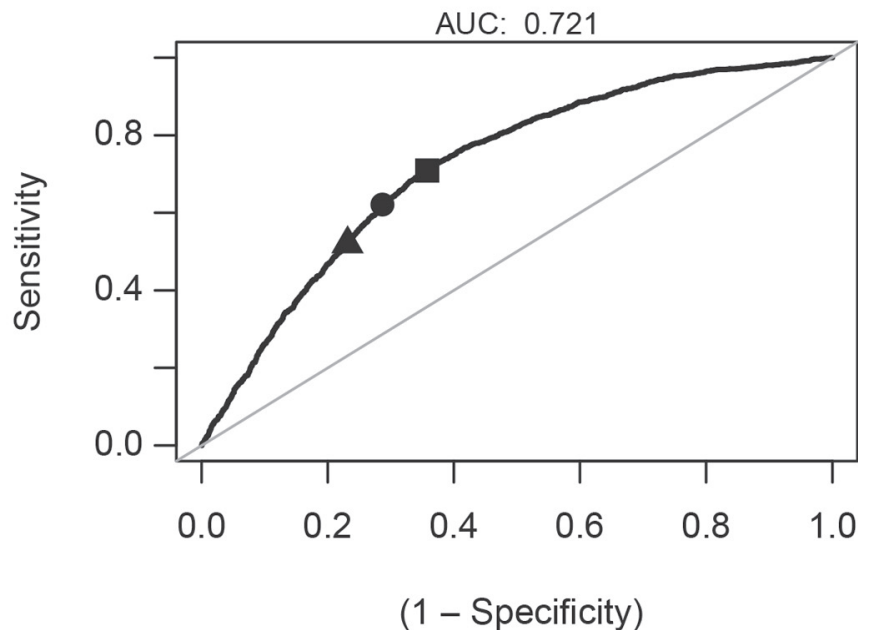

Figure 4. Receiver-operating characteristic (ROC) curves using TempChange to predict calving within 24 and 12 h for parous Holstein cows. TempChange quantifies the decrease in reticulo-rumen temperature relative to a baseline. Baseline $1=$ average of readings for 4 previous days using a $1 \mathrm{~h}$ window from the current reading. Baseline 2 = average of readings for 4 previous days using a $5 \mathrm{~h}$ window from the current reading. An area under the curve $(\mathrm{AUC})>0.50$ indicates that TempChange (reticulo-rumen temperature) provides a better prediction than random guessing. 
large of a drop in Trr and would be missed (low Se) compared with using a smaller temperature drop. Likewise, a threshold of $-0.2^{\circ} \mathrm{C}$ leads to higher Se (more positive tests) but lower Se (more false alarms) because many animals exhibit this size of drop. Thus, use of the $-0.2^{\circ} \mathrm{C}$ threshold would allow an increase in the number of animals monitored during calving, with the trade-off of more false alarms. This may be desirable in practice because it would reduce the possibility of a female calving without necessary supervision. Even if false alarms occur, it may be better to have animals with a false calving alarm being monitored than animals not being monitored and calving without supervision. The threshold value in the current study does not corroborate results obtained by Aoki et al. (2005) and Burfeind et al. (2011), which verified better Se and Sp results for a $-0.3^{\circ} \mathrm{C}$ threshold. This difference could be related to the different anatomic areas evaluated (Hahn et al., 1990; Firk et al., 2002), whereas the heat produced by reticulo-rumen microorganisms provides

\section{Baseline 1 - $24 \mathrm{~h}$}

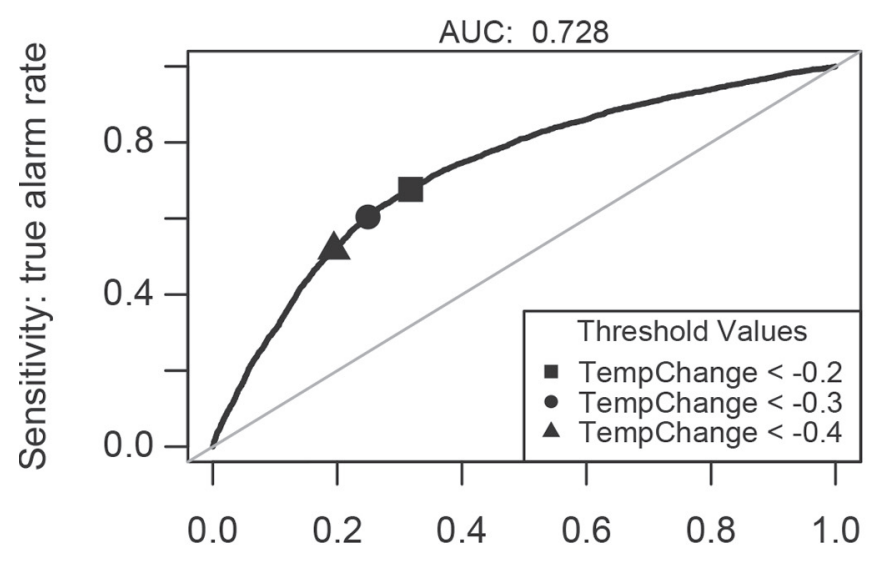

(1 - Specificity): false alarm rate

\section{Baseline 2 - $24 \mathrm{~h}$}

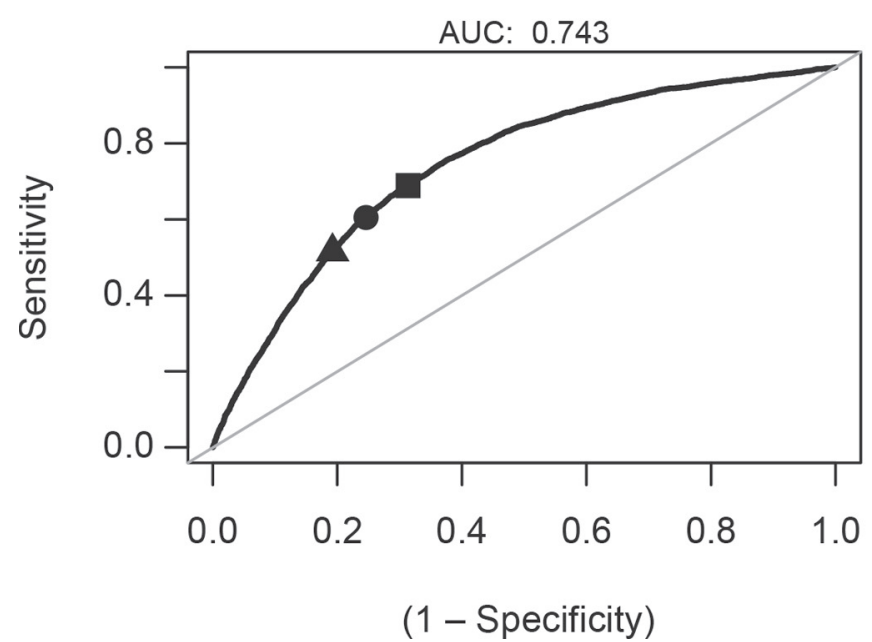

\section{Baseline 1 - $12 \mathrm{~h}$}

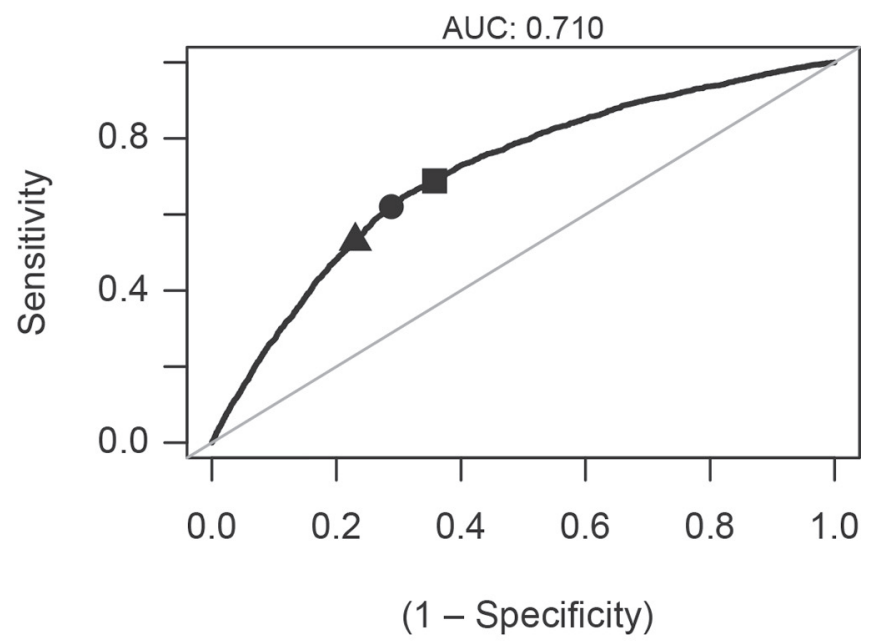

\section{Baseline 2 - $12 \mathrm{~h}$}

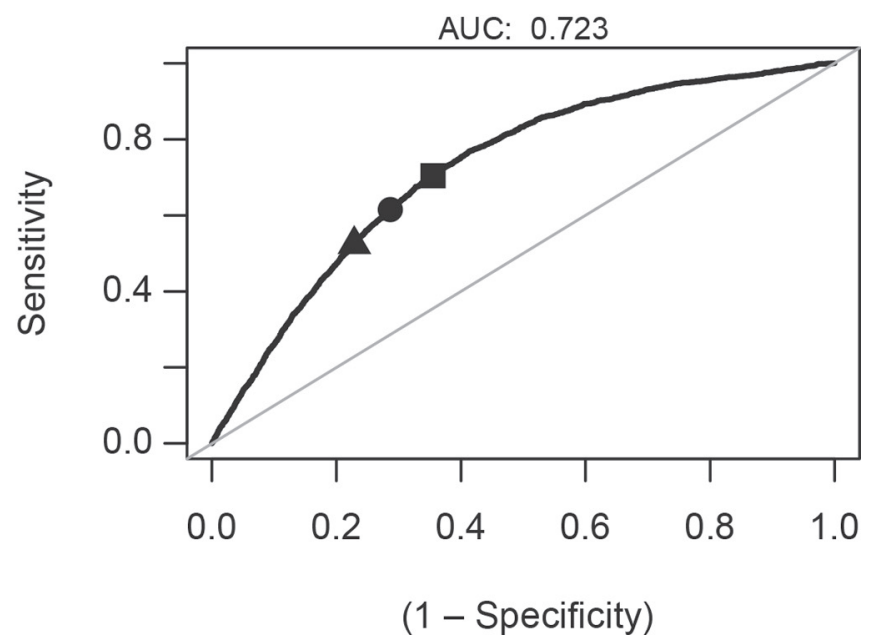

Figure 5. Receiver-operating characteristic (ROC) curves using TempChange to predict calving within 24 and $12 \mathrm{~h}$ for all animals. TempChange quantifies the decrease in reticulo-rumen temperature relative to a baseline. Baseline $1=$ average of readings for 4 previous days using a $1 \mathrm{~h}$ window from the current reading. Baseline $2=$ average of readings for 4 previous days using a $5 \mathrm{~h}$ window from the current reading. An area under the curve $(\mathrm{AUC})>0.50$ indicates that TempChange (reticulo-rumen temperature) provides a better prediction than random guessing. 
Table 5. $\beta$ Estimates (95\% CI in parentheses) for the 12 estimated generalized linear models used to predict calving time in Holstein females ${ }^{1}$

\begin{tabular}{|c|c|c|c|c|}
\hline \multirow[b]{2}{*}{ Group } & \multicolumn{2}{|c|}{ Baseline $1^{2}$} & \multicolumn{2}{|c|}{ Baseline $2^{3}$} \\
\hline & $24 \mathrm{~h}$ & $12 \mathrm{~h}$ & $24 \mathrm{~h}$ & $12 \mathrm{~h}$ \\
\hline Primiparous & $\begin{array}{l}-1.84 \\
(-1.93,-1.73)\end{array}$ & $\begin{array}{l}-1.49 \\
(-1.62,-1.36)\end{array}$ & $\begin{array}{l}-2.01 \\
(-2.13,-1.90)\end{array}$ & $\begin{array}{l}-1.62 \\
(-1.75,-1.48)\end{array}$ \\
\hline & $\begin{array}{l}-1.55 \\
(-1.63,-1.44)\end{array}$ & $\begin{array}{l}-1.36 \\
(-1.48,-1.26)\end{array}$ & $\begin{array}{l}-1.76 \\
(-1.86,-1.65)\end{array}$ & $\begin{array}{l}-1.50 \\
(-1.62,-1.40)\end{array}$ \\
\hline All animals & $\begin{array}{l}-1.67 \\
(-1.74,-1.60)\end{array}$ & $\begin{array}{l}-1.42 \\
(-1.50,-1.34)\end{array}$ & $\begin{array}{l}-1.87 \\
(-1.95,-1.79)\end{array}$ & $\begin{array}{l}-1.56 \\
(-1.64,-1.47)\end{array}$ \\
\hline
\end{tabular}

${ }^{1}$ Each generalized linear model used changes in reticulo-rumen temperature (TempChange) to estimate the probability of calving in the next " $\mathrm{h}$ " $\mathrm{h}(\mathrm{h}=12,24)$. The confidence intervals for $\beta$ that do not contain 0 indicate a statistically significant relationship between TempChange and the probability of calving in the next " $h$ " h. Negative values of $\beta$ indicate the estimated probability of calving increases (non-linearly) as the drop in reticulo-rumen increases.

${ }^{2}$ Baseline 1 = average of readings for 4 previous days using a $1 \mathrm{~h}$ window from the current reading. Differences in observed temperature and baseline 1 were used to calculate TempChange.

${ }^{3}$ Baseline 2 = average of readings for 4 previous days using a $5 \mathrm{~h}$ window from the current reading. Differences in observed temperature and baseline 2 were used to calculate TempChange.

a Trr around $0.5^{\circ} \mathrm{C}$ higher than body temperature (Bewley et al., 2008), which could explain differences between anatomic areas.

Noting the trade-off between Se and Sp, we used the DOR to provide a single measure of threshold performance. Values of DOR in Tables 2, 3, and 4 indicated that a TempChange threshold of $-0.2^{\circ} \mathrm{C}$ provided the best predictive performance (largest DOR) of all thresholds considered. For all animals, predicting calving in the next $24 \mathrm{~h}$ led to slightly better test performance than predicting calving within $12 \mathrm{~h}$. When predicting calving within the next $24 \mathrm{~h}$, predictions were slightly better for primiparous than parous Holstein females but similar between parous and primiparous Holstein females when predicting calving within the next $12 \mathrm{~h}$. Finally, the DOR indicated that BL2 provided better predictions than BL1.

After removing Trr readings below $37.7^{\circ} \mathrm{C}$, we were able to provide evidence of the association between a change in Trr and calving that, following the further development and testing of an algorithm, may be used as an indicator of calving. We defined 2 baseline temperatures that could be used to compute a change in Trr which we called TempChange. We used TempChange and observed calving times to estimate GLM that modeled the probability of an animal calving within the next 12 or $24 \mathrm{~h}$. The GLM indicated that change in Trr was statistically significantly related to the probability of calving. We evaluated the predictive performance of 3 different thresholds for changes in Trr in primiparous and parous Holstein females for the 2 different baselines and 2 prediction times. Results provide evidence that a drop in Trr of $-0.2^{\circ} \mathrm{C}$ or greater was associated with onset of calving and that Trr may be a useful tool in creating a calving prediction algorithm to be implemented in practice.

\section{ACKNOWLEDGMENTS}

The authors thank DVM Systems LLC (Greeley, CO) for supplying the technologies used in this study and for technical support, and Bella Holsteins (Platteville, $\mathrm{CO}$ ) for providing the animals used in this study and their assistance during the project.

\section{REFERENCES}

Aoki, M., K. Kimura, and O. Suzuki. 2005. Predicting time of parturition from changing vaginal temperature measured by datalogging apparatus in beef cows with twin fetuses. Anim. Reprod. Sci. $86: 1-12$

Bellows, R. A., D. J. Patterson, P. J. Burfening, and D. A. Phelps. 1987. Occurrence of neonatal and postnatal mortality in range beef cattle. II. Factors contributing to calf death. Theriogenology 28:573-586.

Bewley, J. M., M. W. Grott, M. E. Einstein, and M. M. Schutz. 2008. Impact of intake water temperatures on reticular temperatures of lactating dairy cows. J. Dairy Sci. 91:3880-3887.

Boehmer, B. H., C. L. Bailey, E. C. Wright, and R. P. Wettemann. 2009. Effects of temperature of consumed water on rumen temperature of beef cows. Accessed Jul. 10, 2014. http://www.ansi.okstate.edu/ research/2009/2009\%20Boehmer\%20Research\%20Report.pdf.

Burfeind, O., V. S. Suthar, R. Voigtsberger, S. Bonk, and W. Heuwieser. 2011. Validity of prepartum changes in vaginal and rectal temperature to predict calving in dairy cows. J. Dairy Sci. 94:5053-5061.

Cooper-Prado, M. J., N. M. Long, E. C. Wright, C. L. Goad, and R. P. Wettemann. 2011. Relationship of rumen temperature with parturition and estrus of beef cows. J. Anim. Sci. 89:1020-1027.

Czaja, J. A., and P. C. Butera. 1986. Body temperature and temperature gradients: Changes during the estrous cycle and in response to ovarian steroids. Physiol. Behav. 36:591-596.

Dye, T. K. 2005. Rumen temperature boluses for monitoring health of feedlot cattle. MS Thesis. Oklahoma State Univ., Stillwater. 
El-Osta, H. S., and M. J. Morehart. 2000. Technology adoption and its impact on production performance of dairy operations. Rev. Agric. Econ. 22:477-498.

Firk, R., E. Stamer, W. Junge, and J. Krieter. 2002. Automation of oestrus detection in dairy cows: A review. Livest. Prod. Sci. $75: 219-232$.

Glas, A. S., J. G. Lijmer, M. H. Prins, G. J. Bonsel, and P. M. Bossuyt. 2003. The diagnostic odds ratio: A single indicator of test performance. J. Clin. Epidemiol. 56:1129-1135.

Hahn, G. L., R. A. Eigenberg, J. A. Nienaber, and E. T. Littledike. 1990. Measuring physiological responses of animals to environmental stressors using a microcomputer-based portable datalogger. J. Anim. Sci. 68:2658-2665.

Hampl, R., L. Stárka, and L. Janský. 2006. Steroids and thermogenesis. Physiol. Res. 55:123-131.

Kadzere, C. T., M. R. Murphy, N. Silanikove, and E. Maltz. 2002. Heat stress in lactating dairy cows: A review. Livest. Prod. Sci. $77: 59-91$.

Khanal, A. R., J. Gillespie, and J. MacDonald. 2010. Adoption of technology, management practices, and production systems in US milk production. J. Dairy Sci. 93:6012-6022.

Kumar, R., and A. Indrayan. 2011. Receiver operating characteristic (ROC) curve for medical researchers. Indian Pediatr. 48:277-287.

Lammoglia, M. A., R. A. Bellows, R. E. Short, S. E. Bellows, E. G Bighorn, J. S. Stevenson, and R. D. Randel. 1997. Body temperature and endocrine interactions before and after calving in beef cow. J. Anim. Sci. 75:2526-2534.

Martinez, E. Z., F. Louzada-Neto, and B. P. Basílio. 2003. Analysis of diagnostic tests using ROC curves. Cad. Saude Colet. 11:7-31.

Matsas, D. J., R. L. Nebel, and K. D. Pelzer. 1992. Evaluation of an on-farm blood progesterone test for predicting the $\mathrm{d}$ of parturition in cattle. Theriogenology 37:859-868.

McCullagh, P., and J. A. Nelder. 1989. Generalized Linear Models. Vol. 37. CRC Press, Boca Raton, FL.

McGuirk, B. J., R. Forsyth, and H. Dobson. 2007. Economic cost of difficult calvings in the United Kingdom dairy herd. Vet. Rec. 161:685-687.

Mee, J. F. 2008. Prevalence and risk factors for dystocia in dairy cattle: A review. Vet. J. 176:93-101.

Mee, J. F., D. P. Berry, and A. R. Cromie. 2011. Risk factors for calving assistance and dystocia in pasture-based Holstein-Friesian heifers and cows in Ireland. Vet. J. 187:189-194.

Nakayama, T., M. Suzuki, and N. Ishizuka. 1975. Action of progesterone on preoptic thermosensitive neurons. Nature 258:80.

NCAR-Research Applications Laboratory. 2014. Verification: Weather Forecast Verification Utilities. R package version 1.41.

Obuchowski, N. A. 2003. Receiver operating characteristic curves and their use in radiology. Radiology 229:3-8.

Palombi, C., M. Paolucci, G. Stradaioli, M. Corubolo, P. B. Pascolo, and M. Monaci. 2013. Evaluation of remote monitoring of parturition in dairy cattle as a new tool for calving management. BMC Vet. Res. 9:191-200.

Patel, O. V., N. Takenouchi, T. Takahashi, M. Hirako, N. Sasaki, and I. Domeki. 1999. Plasma oestrone and oestradiol concentrations throughout gestation in cattle: relationship to stage of gestation and fetal number. Res. Vet. Sci. 66:129-133.
Robertshaw, D. 2004. Thermal regulation and the thermal environment. Pages 962-973 in Dukes' Physiology of Domestic Animals. 12th ed. Cornell University Press, Ithaca, NY.

Robin, X., N. Turck, A. Hainard, N. Tiberti, F. Lisacek, J. C. Sanches, and M. Muller. 2011. pROC: An open-source package for R and $\mathrm{S}+$ to analyze and compare ROC curves. BMC Bioinformatics $12: 77$.

Shah, K. D., T. Maeda, T. Hidaka, and Y. Ogata. 2007. Estrone sulfate and progesterone profiles during late gestation in recipient cows transferred embryos produced by nuclear transfer and in vitro fertilization. J. Reprod. Dev. 53:1237-1246.

Sievers, A. K., N. B. Kristensen, H. J. Laue, and S. Wolffram. 2004 Development of an intraruminal device for data sampling and transmission. J. Anim. Feed Sci. 13:207-210.

Silva, J. E. 2003. The thermogenic effect of thyroid hormone and its clinical implications. Ann. Intern. Med. 139:205-213.

Silva, J. E. 2006. Thermogenic mechanisms and their hormonal regulation. Physiol. Rev. 86:435-464.

Smith, V. G., L. A. Edgerton, H. D. Hafs, and E. M. Convey. 1973. Bovine serum estrogens, progestins and glucocorticoids during late pregnancy, parturition and early lactation. J. Anim. Sci. 36:391396.

Stachenfeld, N. S., C. Silva, and D. L. Keefe. 2000. Estrogen modifies the temperature effects of progesterone. J. Appl. Physiol. 88:16431649

Streyl, D., C. Sauter-Louis, A. Braunert, D. Lange, F. Weber, and H. Zerbe. 2011. Establishment of a standard operating procedure for predicting the time of calving in cattle. J. Vet. Sci. 12:177-185.

Tsai, C. L., K. Kanosue, and K. Matsumura. 1992. Effects of estradio treatment on responses of rat preoptic warm sensitive neurons to progesterone in vitro. Neurosci. Lett. 136:23-26.

Tsai, C. L., K. Matsumura, and T. Nakayama. 1988. Effects of progesterone on thermosensitive neurons in preoptic slice preparations. Neurosci. Lett. 86:56-60.

USDA Economic Research Service. 2007. Profits, costs, and the changing structure of dairy farming. Economic Research Report. Fed. Regist. 47:1-35.

Wettemann, R. P., and H. D. Hafs. 1973. LH, prolactin, estradiol and progesterone in bovine blood serum during early pregnancy. J. Anim. Sci. 36:51-56.

Wright, I. A., I. R. White, A. J. Russel, T. K. Whyte, and A. J. McBean. 1988. Prediction of calving date in beef cows by real-time ultrasonic scanning. Vet. Rec. 123:228-229.

Zaborski, D., W. Grzesiak, I. Szatkowska, A. Dybus, M. Muszynska, and M. Jedrzejczak. 2009. Factors affecting dystocia in cattle. Reprod. Domest. Anim. 44:540-551.

Zhu, W., N. Zeng, and N. Wang. 2010. Sensitivity, specificity, accuracy, associated confidence interval and ROC analysis with practical SAS ${ }^{\circledR}$ implementations. Pages 1-9 in NESUG Proc.: Health Care and Life Sciences, Baltimore, MD.

Zweig, M. H., and G. Campbell. 1993. Receiver-operating characteristic (ROC) plots: A fundamental evaluation tool in clinical medicine. Clin. Chem. 39:561-577. 